\title{
Leiomyosarcoma and Endometrial Stromal Sarcoma Pathologic Regional Lymph Nodes TNM Finding v7
}

National Cancer Institute

\section{Source}

National Cancer Institute. Leiomyosarcoma and Endometrial Stromal Sarcoma

Pathologic Regional Lymph Nodes TNM Finding v7. NCI Thesaurus. Code C89596.

A pathologic finding about one or more characteristics of leiomyosarcoma and endometrial stromal sarcoma, following the rules of the TNM AJCC v7 classification system as they pertain to staging of the regional lymph nodes. 